\title{
Cultura e transformação do trabalho no porto de Santos*
}

\author{
João Carlos Gomes** \\ Luciano Antonio Prates Junqueira***
}

SumÁrio: 1. Introdução; 2. Concepções teóricas; 3. Cultura e experiência portuária; 4. Mudança, transformação do trabalho e nova ordem cultural; 5. Considerações finais.

SUMmARY: 1 Introduction; 2. Theoretical concepts; 3 . Culture and port experience; 4. Change, labor transformation and new cultural order; 5. Final remarks.

Palavras-chave: cultura; trabalho; porto.

KEY WORDs: culture; labor; port.

Este artigo analisa, pela perspectiva da cultura, os significados que os estivadores atribuem às mudanças que se processam no porto de Santos, colocando em evidência o impacto produzido pela transformação portuária sobre os valores constituídos ao longo de sua experiência histórica. Os primeiros resultados mostram que a atual organização do trabalho, orientada pelas novas tecnologias e pelos novos atores no porto, se apresenta para os estivadores como um estranhamento, visto que seu significado ainda se inscreve na ordem cultural passada.

\footnotetext{
* Artigo recebido em fev. 2007 e aceito em mar. 2008.

** Professor assistente doutor da Universidade Católica de Santos; doutor em história social pela Pontifícia Universidade Católica de São Paulo (PUC-SP); mestre em administração pela Universidade Metodista de São Paulo. Pesquisador no Projeto Transformação das Relações de Trabalho no Porto de Santos, do Mestrado em Gestão de Negócios da Universidade Católica de Santos. Endereço: Av. Vicente de Carvalho, 36, ap. 83 - Santos - CEP 11045-500, São Paulo, Brasil. E-mail: profjgomes@uol.com.br

*** Professor titular da Pontifícia Universidade Católica de São Paulo (PUC-SP). Coordenador do Programa de Estudos Pós-Graduados em Administração da PUC-SP; professor assistente doutor do Programa de Gestão de Negócios da Universidade Católica de Santos e coordenador do Projeto de Pesquisa Transformação das Relações de Trabalho no Porto de Santos. Endereço: Rua Sabará, 318, ap. 46 - CEP 01239-010, São Paulo, SP, Brasil. E-mail: junq@pucsp.br.
} 


\section{Culture and labor transformation at the port of Santos}

This article analyzes, from a cultural perspective, the meanings that stevedores give to the changes that are taking place at the port of Santos, emphasizing the impact that these changes have on the values built along the port's history. The first results show that the current organization of labor, oriented by new technologies and new port actors, is strange to the stevedores, since its meaning is still linked to the past cultural order.

\section{Introdução}

Os estivadores do porto de Santos representam um tipo de operariado que desenvolveu formas de organização do trabalho, de ações políticas, valores e crenças, muito diferentes daquelas forjadas nos espaços fabris clássicos. A organização do trabalho que mantinham sob controle implicava uma estrutura onde chefe e subordinado partilhavam de valores comuns que não estavam inscritos nas formas tradicionais do modo de produção capitalista. Em outras palavras, a forma estrutural do sistema organizativo do trabalho não era exclusivamente dada pelas propriedades objetivas da produção.

A divisão do trabalho nas operações de movimentação de cargas realizadas exclusivamente nos navios não se assemelhava ao modelo clássico de produção. Chefe e subordinados articulavam suas ações no interior de uma cultura onde autonomia, permanência e hierarquia pertenciam a um único sistema de relações, que não era comandado pelas formas produtivas capitalistas (planejamento, operação, controle) o que lhes dava a singularidade de grupo que veio a ser chamado de "empregados sem patrões". O sentido de coletivo que daí emerge é uma construção simbólica única, uma categoria primária do seu pensamento.

As formas de organização que desenvolveram no próprio fazer-se inscrito no trabalho ocasional, nas suas ações com o Estado autocrático e paternalista, mediador das relações com o capital até 1980, na base tecnológica da indústria marítima desse mesmo período - que condicionava trabalho manual em grande escala, pequenas inversões de tecnologia em equipamentos e nos longos anos sem alteração nos métodos de trabalho - foram construtoras de um sistema de valores e crenças que definiam a própria forma de suas ações. Seus laços de pertencimento se desenvolveram no interior de um trabalho estável e no ofício orientado pela ação prática. A base técnica do transporte marítimo e o sistema de governança que perdurou no porto em todos os anos anteriores a 1993 tiveram peso considerável na gestão autônoma que detinham sobre a atividade exclusivamente manual, vista como trabalho efetivo. 
Não precisavam de escola para realizá-lo. A condição de trabalhadores avulsos assegurava-lhes o controle sobre o mercado de trabalho e reforçava o sentido de pertencimento em relação à administração portuária. Esse sistema lhes fornecia os significados que moldavam suas ações no enfrentamento das contingências e estruturava as formas simbólicas que orientavam as percepções sobre sua existência. Essas formas se reproduziram em função dos diferentes eventos históricos que enfrentaram; e a compreensão sobre a maneira como lidaram com a transformação torna a investigação de sua experiência um imperativo.

$\mathrm{Na}$ atual fase de modernização portuária eles são vistos como uma categoria que resiste à inovação. As resistências ao processo de modernização não se inscrevem no plano econômico ou técnico, não estão vinculadas exclusivamente a uma dimensão operacional, mas sim associada a elementos culturais.

Pouco se tem estudado sobre sua cultura e a ausência de aprofundamento sobre ela tem impedido que políticas de trabalho voltadas para novas formas organizativas no porto possam ser implementadas satisfatoriamente.

Um dos pontos críticos da atual fase da mudança está nos embates que incluem de um lado as ações de resistência dos estivadores e do outro as imposições postas pelas forças transformadoras: capital, Estado e instituições afins. Os impasses ocorrem desde 1993, ano da implementação da Lei oo 8.630, conhecida como Lei de Modernização dos Portos, onde as ações estratégicas adotadas pelas forças modernizadoras tanto em nível nacional quanto local, levam em consideração o pressuposto da superioridade da razão técnica e a sua capacidade de conformar a realidade social, tornando "natural" a dependência dos trabalhadores à estrutura totalizante da tecnologia e do mercado. Esse pressuposto considera que desenvolvimento tecnológico é igual a progresso social, o que exclui os problemas dele advindos como precarização do trabalho e desestruturação de culturas.

A problemática, aos olhos dessas forças, está centrada na idéia de que sua força cultural passada insiste em manter-se ativa num ambiente em que não cabe mais o mesmo significado e, por essa razão, é responsável pela lentidão em alcançar os padrões de eficiência para tornar o porto competitivo. Elas optam exclusivamente pela estratégia de implementação dos elementos inscritos na lógica do mercado em que o império da produtividade pede um trabalhador polivalente, que apresente maior comprometimento com o seu trabalho, capaz de adiar compensação financeira, e conseqüentemente aceite a redução do contingente. Essa nova forma de gestão do trabalho impacta os valores e os significados da profissão constituídos durante toda a história de vida da categoria. 
A ausência de ações que levem em consideração a existência da ordem cultural desenvolvida no período anterior à Lei oㅡ 8.630, em que o Estado paternalista e o sindicato controlador do trabalho no porto eram resultantes da base técnica do transporte marítimo e dos padrões de competitividade da época, tem sido responsável por muitos dos impasses que ainda prevalecem no porto santista. O problema da permanente resistência está vinculado a essa prevalência da ordem econômica sobre a cultural. A nova estrutura social portuária, que opera como reflexo direto da legislação que regulamenta as relações de trabalho após 1993, não leva em consideração que os significados construídos por esses trabalhadores no passado têm existência cultural efetiva integrada a um esquema simbólico historicamente constituído e, portanto, não é a mudança que faz a cultura, mas a cultura que faz a mudança.

Este artigo, ao resgatar a noção de experiência vivida na forma de representações culturais, propõe um diálogo entre antropologia e estudos organizacionais com o objetivo de compreender as formas de posicionamento da força de trabalho estivadora diante de um novo paradigma tecnológico e organizacional.

A preferência teórica se deve à evidência de que a experiência dos estivadores se inscreve na relação entre a ação produtiva no mundo e a organização simbólica da experiência, o que nos remete à investigação das relações entre ordem cultural e mudança. O cultural entendido como aquele que tem, como especificidade de seu conteúdo, o significado.

A primeira parte deste artigo trata dos aportes conceituais que norteiam o trabalho. O estudo da "cultura" tem o objetivo de dar embasamento sobre as referências significantes que se desenvolvem na trajetória de vida dos estivadores, o que permite entendê-los no processo de transformação. A análise sobre a reestruturação produtiva coloca em evidência os aspectos sociais que presidem as relações de trabalho que emergem de novos paradigmas produtivos com o objetivo de situar as contradições e ambigüidades que impactam a vida dos estivadores.

Na segunda parte vemos a cultura e a experiência portuária, procurando delinear as especificidades do trabalho e das vivências e significados daí extraídos.

Na terceira parte são analisadas as questões conjunturais e estruturais que envolvem a mudança e os significados que os estivadores atribuem a elas. Incluem-se aí entrevistas realizadas com lideranças do sindicato dos estivadores em 2007.

O campo de observação contempla dois grandes pilares da transformação: a forma de utilização da força de trabalho e o sistema de governança no porto. 
Finalmente, temos os impasses a partir da evidência de que a transformação no porto não contempla elementos que articulam os componentes culturais que se desenvolvem em termos de propriedades materiais e sociais.

\section{Concepções teóricas}

\section{Cultura}

Cultura é um conceito que na perspectiva antropológica percorreu um longo caminho em busca do entendimento sobre a natureza do homem. Os evolucionistas $^{1}$ do século XIX postulavam a idéia de que as sociedades seguiam o seu curso histórico por meio de três estágios: a selvageria, o barbarismo e a civilização. Franz Boas (1858-1949) elabora sua reação ao evolucionismo e funda a abordagem multilinear que considerava cada grupo humano se desenvolvendo por caminho próprio. As modernas teorias sobre a cultura seguem dois caminhos. O primeiro, de acordo com Sahlins e colaboradores (citados por Laraia, 2000:60), considera a cultura:

sistemas (de padrões e comportamentos socialmente transmitidos) que servem para adaptar as comunidades humanas aos seus embasamentos biológicos, incluindo tecnologias e modos de organização econômica, padrões de estabelecimento, de organização social e política, crenças e práticas religiosas e assim por diante.

O segundo considera a cultura sistemas simbólicos (Geertz, 1989). Para Gertz os símbolos e significados são pelos atores (membros do sistema cultural), entre eles, mas não dentro deles.

Marshall Sahlins, antropólogo da escola americana, trouxe para a análise "o significado" como a propriedade essencial do objeto cultural, e o uso de símbolos como uma faculdade específica do homem. Para Salense, cada tipo de sociedade é definido por uma fonte privilegiada de simbolismo. A sociedade tribal baseia-se na metáfora do parentesco e o foco simbólico das chefias é

\footnotetext{
${ }^{1}$ Segundo Laraia (2000), a evolução teria raízes em uma unidade psíquica onde todos os grupos humanos teriam o mesmo potencial de desenvolvimento, embora uns tivessem mais adiantado que outros. As sociedades, por essa abordagem, seguiriam o seu curso histórico por meio de três estágios: selvageria, barbarismo e civilização.
} 
o das religiões oficiais, enquanto na cultura ocidental a economia constitui a primeira área de produção simbólica (Kuper, 2002:221).

Sahlins (1997), analisando o conceito de cultura atual, mostra a resistência das culturas perante a expansão capitalista ocidental. Algumas culturas não apenas sobrevivem como estão se tornando mais fortes, pois os atores delas estão interagindo com o capitalismo sem perder o sentido de si mesmos. Atribuem às coisas novas dessa interação novos significados a partir de suas tradições. Eles vêm tentando incorporar o sistema mundial a uma ordem ainda mais abrangente: seu próprio sistema de mundo. A cultura dos estivadores se apresenta como um desses tipos. Ainda permanecem os espaços exclusivamente masculinos, a ostentação de virilidade, as disputas pelas oportunidades de emprego, a ausência demarcada entre tempo de trabalho e de lazer, elementos que atuam como força de resistência à perda de controle da mãode-obra pelo sindicato, e também a ausência das greves de solidariedade, de formas de sociabilidade forjadas em um conjunto de redes de relações tecidas nos bairros, no trabalho e nas relações com outras categorias profissionais, igualmente esvaziadas.

Estudar a sua cultura nos remete à imersão nesse "modo de ser", em que estão embutidos múltiplos significados e sentidos que extraem a partir das suas condições reais de existência. A percepção que adquirem de si próprios e dos objetivos de suas vidas, durante as transformações produtivas do mundo, são determinantes para a construção de sua cultura.

Sahlins considera a cultura uma estrutura significativa interposta entre as circunstâncias e os costumes, o que deixa explícita a ordem simbólica na atividade material. $\mathrm{O}$ trabalho como atividade material e social é produtor de símbolos construtores de significados.

Os esquemas culturais são por aí ordenados porque os significados são reavaliados quando realizados na prática (Sahlins, 1985:7). Para Sahlins, a razão significativa é uma qualidade distintiva do homem não pelo fato de ele viver num mundo material, mas porque, ao compartilhar com todas as forças que se objetivam materialmente, o faz a partir de esquemas significativos criados por si próprio. A cultura não é expressão das formas de produção, pelo contrário, as formas de produção é que se desdobram em termos da cultura, ou seja, não é mais a sua própria forma, mas incorporada como significado, o que a torna uma variável independente.

As estruturas significativas, produto da atividade material, são entendidas como o resultado do conjunto de ações dos agentes interessados, e expressam "a realização prática das categorias culturais, em um contexto histórico" (Sahlins, 1985:15). Na experiência dos estivadores elas foram duplamente 
vivenciadas por um tipo de sociabilidade que inclui o comunitário e o associativo. A noção de comunidade está ligada a um sentimento de solidariedade, vinculado à ordem emocional e à noção de associativismo, à união e ao equilíbrio de interesses racionalmente motivados em relação a valores e resultados. Dependendo do tempo em que foi vivida, tem raízes profundas.

Segundo Sahlins (2004), as pessoas usam as ordens culturais para moldar sua construção e ação no mundo e este, normalmente, está sempre em consonância com elas. Quando ocorre uma transformação estrutural, as pessoas tendem a reproduzir alguns aspectos da cultura tradicional, pois consideram que elas ainda estão em ação. A conseqüência de ver o mundo por meio da sua cultura é a propensão em considerar o seu modo de vida como o mais correto e natural.

A cultura - como definidora de um modo de vida - tem a qualidade de conformar-se com as pressões materiais, a partir de significados definidos que nunca são os únicos possíveis, que se multiplicam. As implicações sociais da atual transformação não estão inscritas no processo tecnológico nem nas suas demandas por uma nova forma de organização do trabalho, mas nas relações sociais que presidem a utilização de ambas. A forma e significação criadas pela transformação são articuladas sob a condição de meios e fins. As categorias culturais são colocadas em jogo e, nesse contexto, só se atualizam por meio de uma estrutura de reciprocidades que não está inscrita no quadro da atual mudança, pois maior comprometimento com o trabalho, sem compensação financeira, e redução do contingente são elementos desestruturadores da sua cultura.

A implementação de um novo paradigma tecnológico e organizacional no porto, ao modificar o padrão de distribuição do trabalho e demandar o surgimento de um "novo trabalhador portuário", agora com maiores habilidades cognitivas, multifuncional e participativo, inaugura uma cultura de empresa que se opõe à cultura portuária vigente.

\section{Reestruturação produtiva e relações de trabalho}

A história do homem é caracterizada pela sua capacidade de exercer domínio sobre a natureza, procurando transformá-la em algo útil e que atenda às suas necessidades. Esse controle ao longo da história vem se complexificando e culmina hoje na busca do controle do trabalho pela apropriação do seu conteúdo subjetivo. Isso implica uma transferência dos saberes e fazeres dos trabalhadores para o espaço do capital. Os conhecimentos dos trabalhadores 
são incorporados aos elementos mecânicos do processo de trabalho, por meio das máquinas. A base técnica em transformação resulta na constatação de que máquinas passam a sintetizar de modo sistêmico um conjunto de tarefas anteriormente realizadas pelos trabalhadores. Estes, por sua vez, passam a se ajustar às características das máquinas. Os graus de liberdade e de autonomia que estavam presentes nos processos anteriores passam por nova reconfiguração e o trabalhador perde a condição de sujeito do processo de trabalho, transformando-se em objeto desse processo (Ruas, 1985:27). O controle sobre conteúdo subjetivo do trabalho torna-o mais concreto, objetivo e gerenciável, e possibilita o desenvolvimento de melhores formas de planejamento, elemento necessário para a estratégia competitiva das empresas. Diante dessa realidade, alguns tipos de trabalho que no passado se caracterizavam por baixo nível de escolaridade e atividade produtiva vinculada à experiência prática e manual, vêm sofrendo forte impacto com a transformação, caso dos estivadores nos portos. Há uma tensão permanente por meio da qual resistências e negociações estão continuamente presentes. A ação dos trabalhadores é motivada pelos contrastes e conflitos que daí emergem e quase sempre a análise sobre o problema busca ênfase nos aspectos econômicos, materiais e estruturais que revestem os conflitos.

Os conflitos se justificam, pois a reestruturação produtiva a partir da conjuntura política e econômica da década de 1970 do século XX, analisada por Gitahy, Leite e Rabelo (1993), é um processo que se dá no marco de um padrão de concorrência basicamente dirigido a um mercado interno em expansão, onde o padrão de gestão da força de trabalho se caracterizava pela rotinização (Fleury, 1983) e formas predatórias de uso da força de trabalho (Abramo, 1999; Carvalho, 1987).

Baseando-se num forte autoritarismo, o gerenciamento do trabalho caracterizou-se pela extrema parcelização das tarefas, pelo uso extensivo da força de trabalho não-qualificada, pela adoção de complexas estruturas de cargos e salários, voltadas para estabelecer a divisão do coletivo operário e o controle sobre os trabalhadores. A crise desse padrão de uso da força de trabalho, nos anos 1980, apresentada a partir de vários estudos, caso de Gitahy (1983), Leite (1994), Carvalho (1987), Rabelo (1993), põe em evidência a dimensão dos conflitos advindos da transformação, que ocupa também lugar de destaque na agenda de estudos sobre trabalhadores portuários.

Salerno (1994) mostra que a reestruturação produtiva tem sua lógica derivada de um contexto social, político e econômico marcado pelas crises financeiras de concorrência intercapitalista e de conflitos entre capital-trabalho, relativos à organização e controle da produção e do trabalho. E colocam para 
as empresas novas necessidades de integração, para dar saltos de produtividade necessários, devido tanto ao acirramento da concorrência quanto aos entraves sociais colocados às formas tradicionais de organização da produção e do trabalho, caso específico do trabalho avulso nos portos mundiais e brasileiros.

\section{Cultura e experiência portuária}

A formação da cultura portuária brasileira tem, no Estado, um ator de especial relevância, pois não só foi mediador das relações entre capital trabalho como foi regulador das normas que possibilitaram a construção dos elementos estruturantes da identidade dos estivadores.

Como categoria de sindicato avulso, os estivadores tinham seu salário administrado pelo Estado e percebido por meio da entidade estivadora, agência intermediária que representava no porto os armadores. Além da remuneração normal, os estivadores tinham direito a $25 \%$ de adicional para o segundo turno de trabalho aos sábados, adicional de 35\% para mercadorias que necessitem material de proteção (insalubridade), adicional de $30 \%$ para mercadorias inflamáveis (periculosidade), pagamento integral do repouso semanal remunerado inclusive nos feriados, pagamento adicional de 30\% do período de serviço interrompido por motivo de chuva, direitos que foram adquiridos numa conjuntura em que o Estado populista, a partir de 1950, negociava com os trabalhadores seu projeto corporativista e que perdurou até o final dos anos 1990.

A remuneração era significada como símbolo de condições de vida, como no depoimento de Lael de Azevedo (2007): “...no meu tempo, a gente podia mostrar a carteira preta da estiva no comércio e fazia qualquer negócio, era um sinônimo de credibilidade". O Decreto-Lei no 5.452, de 1을 de maio de 1943, que regulamenta o trabalho de estiva definia os contornos significantes atribuídos a ela:

Art. 254. Estiva de embarcações é o serviço de movimentação das mercadorias a bordo, como carregamento ou descarga, ou outro de conveniência do responsável pelas embarcações, compreendendo esse serviço a arrumação e a retirada dessas mercadorias no convés ou nos porões.

Art. 255. O serviço de estiva compreende: a) a mão-de-obra de estiva, que abrange o trabalho braçal de manipulação das mercadorias, para sua movimentação ou descarga ou carregamento, ou para sua arrumação, para o transporte 
aquático, ou manejo dos guindastes de bordo, e a cautelosa direção das operações que estes realizam, bem como a abertura e fechamento das escotilhas da embarcação principal e embarcações auxiliares e a cobertura das embarcações auxiliares.

Art. 257. A mão-de-obra na estiva das embarcações, definida na alínea "a" do art. 255 só poderá ser executada por operários estivadores ou por trabalhadores em estiva de minérios nos portos onde os houver especializados, de preferência sindicalizados, devidamente matriculados nas Capitanias dos Portos ou em suas Delegacias ou Agências.

A profissão ganha sentido não porque se inscreve somente nas propriedades objetivas do trabalho, mas também na exclusividade do ofício, no controle do processo de trabalho, condições que se objetivavam por meio das articulações do sindicato com o Estado.

O significado que atribuíam à vida que levavam tinha estreita ligação com esses direitos. Era a sua própria condição humana, necessária para a existência da sua forma social.

O sindicato não significava exclusivamente o provimento do trabalho, o símbolo a ele atribuído expressava os sentidos de autonomia, de hierarquia consentida e, sobretudo, de pertencimento. Para os estivadores o sindicato era a bandeira simbólica de uma "profissão" que entendiam possuir, um espaço sagrado que devia ser defendido das ameaças externas, um construtor de ordens culturais para moldar a sua construção e ação no mundo, em outras palavras, as garantias da própria vida.

As formas de organização do trabalho dão significado ao ofício a partir das articulações com o Estado (a DTM) e com a lógica produtiva:

Antes de ser matriculado o trabalhador era eventual. Ele trabalhava com a carteira profissional. Era o bagrinho. Ele tinha que atingir um certo número de horas para pleitear a carteira de matriculado na Delegacia de Trabalho Portuário (DTM). Depois que você pegava a carteira de matriculado ele passava um certo número de horas para passar para a condição de sindicalizado. Nesse tempo todo você tava praticamente numa escola. Você sabia as regras até chegar a ser estivador. Então tinha um rodízio de 80 dias para ocupar cargo de chefia. Então eu estou nesse cargo eu vou à parede, nos postos de escalação, subo, aí tem um diretor que também é na forma de rodízio, ele ocupa essa posição como fiscal, esse fiscal é que faz a escalação dos postos... a gente passava três anos fazendo os meus círculos de amizade, com todos os trabalhadores da turma, praticamente, com todos os estivadores para quando após os três anos a gente 
ia mandar de mestre, aí naqueles três anos a gente já sabia as pessoas que me deram trabalho, então quando você entrava na estiva você tinha aqueles três anos pra saber tudo o que tinha no navio, trabalhar, conhecer as pessoas para que quando você fosse mandar de mestre você soubesse as pessoas que você ia levar, cada 80 dias no decorrer do ano a gente mandava de mestre,você tinha aquele círculo de amizade, você tinha mais entrosamentos e a gente era bem mais unido antigamente.

(Depoimento do primeiro secretário do Sindicato dos Estivadores, 2007)

A construção da profissão estava relacionada a cada etapa que o trabalhador vivenciava, etapa que tinha como propriedade fazer a mediação para a realização da seguinte de tal forma que as fases estavam uma dentro da outra. As sociabilidades eram construídas nesse percurso, o que implicava fortalecer o sentido de grupo. "Ser estivador" ganha significado a partir desses elementos estruturantes de sua cultura e dá a dimensão da sua força, o que explica as dificuldades de adaptação às novas formas de organização do trabalho, postas pela mudança.

O trabalho ocasional que lhes fornecia mobilidade constante pelos diversos espaços da cidade constituía-se elemento adicional na formação dos significados de autonomia.

Portanto, a cultura não era exclusivamente uma característica da mente, da estrutura cognitiva dos estivadores, mas também um universo maior, onde ocorriam construções de significados que colocavam, por meio da vida que levavam, a fórmula que usavam para definir o que lhes acontecia.

Os significados de cooperação e amizade também tinham estreita conexão com o processo produtivo, como mostra o relato a seguir de um estivador que ingressou no porto em 1964, dependente da base técnica do transporte marítimo, que se manteve imutável por longos anos, o que dá a medida de sua força.

Naquela época os produtos vinham em barris, tonéis de vinho, de azeitona, e outros produtos salgados que vinham em barricas, a banha vinha acondicionada em latas de banha e nós tínhamos que separar esses produtos para transportar para fora do navio. Nós trabalhávamos em terno de até 12 homens, porque tinha muito serviço, era nos ternos que a gente fazia muita amizade.

A esfera do trabalho em primeiro plano mediava os sentidos de companheirismo, pois "era no terno" que as sociabilidades se efetivavam.

As conexões entre as forças produtivas (Estado, agências de navegação, sindicato) reproduziam relações objetivas de valores subjetivos como poder, hierarquia, trabalho, amizade, que davam significado à condição de estivador. 


\section{Mudança, transformação do trabalho e nova ordem cultural}

Ao se analisar a relação de trabalho no porto entre as décadas de 1930 e 1980, deve-se ter em mente que subjacente ao padrão de racionalização do processo produtivo mediado por um Estado monopolizador de um conjunto de atividades, está uma conjuntura marcada pelo ciclo de industrialização nacional que apresentou ritmo acelerado do emprego e da expansão do produto.

Nas décadas de 1960/70 a conjuntura política, social e econômica, marcada por forte intervencionismo do Estado, impôs aos estivadores novas formas de significação em função das novas relações entre sindicato e Estado e da própria relação do Estado (intervenção militar) com a sociedade. Contudo a força original da ordem cultural que mediava a vida do estivador manteve-se intacta porque as relações produtivas (base técnica e organizativa) não foram alteradas.

A área portuária, monopólio do Estado, não funcionava como um empreendimento produtivo capitalista clássico. Sua gestão não implicava padrões de competitividade entre firmas, modelo dos portos atuais. Os custos operacionais estavam associados à simples interface física de deslocamento (embarque e desembarque de cargas e pessoas) que determinava o conceito de porto da época. Não estava presente nessa dinâmica o processo que contava com as instalações portuárias privatizadas, onde a produtividade do trabalho era guiada pela capacidade de competição e negociação entre as empresas operadoras de terminais privatizados. O núcleo simbólico da existência da classe estava localizado no tipo de trabalho e na remuneração, único estilo facultado pela atividade do trabalho.

O significado atribuído à noção de eficiência estava associado às possibilidades de ganho, uma vez que o trabalho era remunerado por produção, como mostra o relato do primeiro-secretário do Sindicato dos Estivadores: "a eficiência do trabalho você sabia pelo conferente, porque todo o movimento do navio o conferente anotava, quando terminava o trabalho você sabia quanto foi movimentado. Aí você sabia quanto tinha para receber. No passado, quem fazia isso tudo era a estiva".

A divisão social do trabalho lhes fornecia os significados de poder conquistado. As agências de navegação, atores intermediários entre os armadores e os trabalhadores, operavam como mediadoras da organização do trabalho junto ao sindicato e à Capitania dos Portos. Quem fazia chegar ao sindicato o volume de produção envolvido e o montante a ser pago pelo trabalho realizado eram as agências. A movimentação de mercadorias nos conveses ou nos porões das embarcações principais ou auxiliares, incluindo o transbordo, arrumação, peação e despeação, bem como o carregamento e a descarga das 
mesmas, quando realizados com equipamentos de bordo era da responsabilidade do sindicato, que além de estruturar as formas de organização da produção detinha poder exclusivo sobre ela. Desde 1939, se opuseram à existência de intermediários ${ }^{2}$ reivindicando para si os serviços de estivagem. O Estado lhes forneceu esse direito já havia meio século. O discurso de Getulio Vargas em 1939 referindo-se ao Decreto no 1.371, que tratava da regulamentação das entidades estivadoras representantes dos empresários, oferecia os elementos articuladores dos significados de autonomia (Sarti, 1981:39):

tal lei jamais ofenderia os direitos e os interesses de quaisquer estivadores no Brasil, mesmo porque seu único objetivo fora a supressão dos intermediários e a conseqüente redução no preço dos fretes encarecidos por aqueles contratantes da estiva.

Os contramestres, "estivadores chefes" que ganhavam essa condição após três anos de sindicato, tempo entendido como suficiente para adquirir a "experiência" que o cargo requeria, representavam a chefia intermediária, eram responsáveis pelo resultado do trabalho do "terno" (grupo de trabalhadores no interior do porão do navio) e mediador entre as autoridades de bordo e o grupo de trabalhadores. A distribuição dos contramestres pelos navios atracados no porto era realizada por um "diretor", estivador que pelos mesmos critérios adotados para o contramestre assumia essa função maior. As chefias assim constituídas obedeciam a um sistema de rodízio (a cada 80 dias) controlado pelo número de suas matrículas na Delegacia de Transporte Marítimo (DTM) da Capitania dos Portos. Os contramestres escolhiam na parede, local de encontro para requisição da mão-de-obra, os trabalhadores necessários. A hierarquia que operava o processo era percebida como portadora de uma única identidade: o estivador.

Os anos 1980 marcam o início de um grande processo de transformação em termos dos portos nacionais e do porto de Santos. A empresa Gaffrée, Guinle \& Cia. tem sua concessão ${ }^{3}$ encerrada e a partir de 7 de novembro de 1980, a administração do porto passa para as mãos da Companhia Docas do Estado de São Paulo (Codesp).

\footnotetext{
${ }^{2}$ Para administrar os serviços de estiva, a legislação previa a figura da entidade estivadora que representava os interesses do capital no porto.

${ }^{3}$ O Decreto Imperial no 9.979, de 12 de julho de 1888, autorizou o grupo liderado por José Pinto de Oliveira, Cândido Gaffrée e Eduardo Palassin Guinle, como resultado de concorrência pública, a construir e a explorar o porto de Santos pelo prazo de 39 anos - prorrogado a partir do Decreto no 966 , de 7 de novembro de 1890, para 90 anos.
} 
Nesse período, em termos mundiais, vivia-se a desregulamentação do transporte marítimo internacional sob o comando dos principais países desenvolvidos, objetivando a abertura dos mercados ao desenvolvimento de grandes empresas globais de navegação que pertenciam à iniciativa privada. Presencia-se a intensificação do uso do contêiner para o transporte de carga geral proporcionando profundas transformações nos portos mundiais (Velasco e Lima, 1999).

Em 1983, articulações políticas anunciavam um novo tempo e os estivadores, tal qual em períodos mais perturbadores, sentem os riscos. Notas publicadas nos jornais A Tribuna, Cidade de Santos, da cidade de Santos e no O Estado de S. Paulo, em 23 de março de 1983, informavam que no último Encontro Regional da Indústria-Santos, realizado no Holliday Inn para 230 participantes, a palestra proferida pelo presidente da Codesp, Sergio da Costa Matte, destacava a necessidade de unificação das categorias portuárias, a criação de terminais privativos no porto, e de estudos visando afastar os avulsos dos terminais dos portos nacionais. Livro de atas: Sindicato dos Consertadores de Carga e Descarga do Porto de Santos (1983:37).

A economia brasileira passava por uma recessão profunda e o PIB, que havia crescido 9,1\% em 1980, apresentava uma retração de $-3,1 \%$ em 1981 , evoluindo para 1,1\% em 1982 e recuando para 2,8\% em 1983.

No final dos anos 1980 o Brasil se inclui entre os países que iniciam reformas com o objetivo de diminuir a intervenção do Estado na economia dando origem às privatizações.

A Lei no 8.630, promulgada em 25 de fevereiro de 1993, conhecida como Lei de Modernização dos Portos, vem (confirmando as mudanças suspeitadas em 1983) com o propósito de adequar a estrutura dos portos brasileiros ao novo processo.

As estruturas no porto se alteram e entre as mais significativas se destaca:

Capítulo 1 (Da exploração do porto e das operações portuárias)

Art. 1‥ Cabe à União explorar, diretamente ou mediante concessão, o porto organizado.

§1ํ Para os efeitos desta Lei, consideram-se: III - Operador portuário: a pessoa jurídica pré-qualificada para a execução de operação portuária na área do porto organizado;

Art. 18. Os operadores portuários devem constituir, em cada porto organizado, um órgão de gestão de mão-de-obra do trabalho portuário, tendo como finalidade: I - administrar o fornecimento da mão-de-obra do trabalhador portuário e do trabalhador portuário-avulso; II - manter, com exclusividade, o cadastro do 
trabalhador portuário e o registro do trabalhador portuário avulso; III - promover o treinamento e a habilitação profissional do trabalhador portuário, inscrevendo-o no cadastro; IV - selecionar e registrar o trabalhador portuário avulso; $\mathrm{V}$ - estabelecer o número de vagas, a forma e a periodicidade para acesso ao registro do trabalhador portuário avulso; VI - expedir os documentos de identificação do trabalhador portuário; VII - arrecadar e repassar, aos respectivos beneficiários, os valores devidos pelos operadores portuários, relativos à remuneração do trabalhador portuário avulso e aos correspondentes encargos fiscais, sociais e previdenciários.

As mudanças são profundas, pois alteram radicalmente a ordem cultural que ordenava os significados da vida para os estivadores. A introdução da figura do operador portuário - empresas privadas que realizam o embarque e o desembarque das cargas, e a criação por elas, do órgão gestor de mão-deobra (Ogmo) impõem novas relações de trabalho.

Do ponto de vista da presença de novos atores no processo de governança do porto, o Ogmo abala os significados de pertencimento que só faziam sentido com o sindicato. Se o Estado e os armadores no passado garantiam a forma social do sindicato como controlador do mercado de trabalho, agora essa forma social se altera com o Ogmo, pois, como representante do capital, substitui o sindicato nos aspectos primordiais da gestão da força de trabalho avulsa conforme preconiza a Lei no 8.630:

Art. 19. Compete ao órgão de gestão de mão-de-obra do trabalho portuário avulso:

I - aplicar, quando couber, normas disciplinares previstas em Lei, contrato, convenção ou acordo coletivo de trabalho, no caso de transgressão disciplinar, as seguintes penalidades:

a) repreensão verbal ou por escrito;

b) suspensão do registro pelo período de dez a trinta dias;

c) cancelamento do registro;

II - promover a formação profissional e o treinamento multifuncional do trabalhador portuário, bem assim programas de realocação e de incentivo ao cancelamento do registro e de antecipação de aposentadoria;

III - arrecadar e repassar, aos respectivos beneficiários, contribuições destinadas a incentivar o cancelamento do registro e a aposentadoria voluntária.

Observa-se que o conteúdo implica novas formas de controle social da produção, impactando os valores produzidos pela tradição e pelos costumes. Ouvindo trabalhadores obtivemos o seguinte depoimento: 
muitos antigos não aceitaram a vinda do Ogmo, não aceitaram a modernidade, muitos se aposentaram com 70\% e o Ogmo foi a grande causa dessa desunião (...) o Ogmo foi a pior coisa que aconteceu para nós porque acabou com o poder do sindicato, hoje o sindicato na realidade está posto aqui para negociar, hoje ele já não tem poderes para organizar, para fiscalizar, para administrar, hoje nós estamos aqui só para negociar e a vida social do trabalhador caiu muito, porque era tudo no nosso poder, era uma irmandade, hoje está uma bagunça generalizada. Antigamente a posição do segundo secretário operacional do sindicato, ele tinha uma equipe de 80 diretores que eram os olhos dele, junto com essa equipe ele trabalhava, ele ia para bordo, ele ia ver se os trabalhadores estavam no porão dos navios, via se o trabalho estava adequado, ele corria esse cais todo, hoje o segundo secretário não tem mais essa função.

A ordem simbólica é incluída em hierarquia de meios e fins, implicando a aposentadoria dos mais antigos, realizada por um processo de escolha racional que lhes era natural. A nova ordem cultural tem a propriedade de desmanchar "a família", ou seja, enquanto situação vivida, os novos significados expressos nas ações mostram que a cultura-tal-como-constituída perde referência para orientar a vida presente. O relato a seguir mostra essa tendência:

A nova ordem coloca em xeque as estratégias políticas que no passado orientavam as disputas que se apresentavam ...quando a gente quer fazer uma negociação diretamente com o armador a gente pára no Sopesp que é o Sindicato dos Operadores Portuários do Estado de São Paulo, a gente pára ali, não se consegue chegar no armador, então a gente tem que buscar articulação política, os parlamentares, os políticos da cidade, agora para ser sincero, hoje está difícil... Por isso que a gente tá sempre com nossos representantes em Brasília articulando com os parlamentares para ver se a gente traz de volta a nossa aposentadoria especial que nós perdemos. Isso pra nós seria excelente pois num quadro de 3.000 registrados, com a vinda da especial, aposentava 1.000, a gente conseguia enxugar o quadro e conseguia manter o lado financeiro um pouquinho melhor.

A luta que hoje se trava não encontra ressonância nas instituições que no passado estiveram ao lado da categoria. A transformação no sentido mais amplo colocou o Estado distante e os signos do passado que orientavam as ações, quando trazidos para o presente, não encontram relação com os novos signos e as respostas se inscrevem na ordem da cultura passada. A ação do sindicato (seus líderes atuais), portanto, está voltada para tentar manter o 
sentido de pertencimento (do passado) que não tem o mesmo significado no presente, como mostra o relato a seguir:

hoje o sindicato precisa de uma diretoria que passe para o trabalhador uma certa tranqüilidade, o trabalhador não pode chegar aqui e perguntar como é que estão as coisas (...) aí nós respondemos tá tudo ruim?...não, nós dizemos que estamos negociando, nós estamos brigando, sempre incentivando eles (...) a gente não pode passar para eles uma negatividade... mas claro tudo depende da diretoria saber negociar.

Os grandes investimentos realizados pelas empresas operadoras arrendatárias tornou imperativo que as operações desses novos equipamentos fossem realizadas por trabalhadores por eles contratados, pois os padrões de eficiência requeridos ficam sob o seu controle, trazendo para o novo mercado de trabalho a figura do trabalhador vinculado que nasce sob a condição de forte competidor com os trabalhadores avulsos.

As operadoras portuárias investem recursos no sindicato dos trabalhadores vinculados ${ }^{4}$ sob diversas formas com o objetivo de dar maior visibilidade social à transformação. A percepção dos estivadores sobre esse movimento pode ser compreendida no depoimento do segundo secretário do Sindicato dos Estivadores, a seguir:

Essa categoria de vinculado que faz festas na praia gastando bastante dinheiro, não são trabalhadores que saíram dos quadros dos avulsos, eles são trabalhadores registrados do patrão, então aquilo ali é bancado praticamente pelo patrão, mas na realidade, aquele trabalhador, qualquer movimento que eles fizerem para reivindicar uma melhoria, já mandam ele passar no departamento pessoal, porque conosco eles não podem fazer isso, porque a gente faz parte do sindicato, pois quando chega um navio e tem 50 contêineres para desembarcar a gente vai lá desembarca e vamos embora, e eles pagam a gente e acabou, eles não têm vínculo com a gente nem nós com eles. Por isso que eles têm televisão, rádio etc. para mostrar para a opinião pública, para contrapor eles e retaliar o trabalhador avulso.

O depoimento põe às claras que os estivadores usam as ordens culturais passadas para moldar sua construção e ação no mundo presente. Diante

\footnotetext{
${ }^{4}$ Trabalhador vinculado diz respeito àquele que é contratado pela operadora portuária em caráter permanente, aquele que trabalha tendo ou não navio no porto.
} 
das contradições inerentes à mudança, eles reproduzem aspectos da cultura tradicional (tradição de lutas ideológicas), como elementos de resistência ao avanço das forças transformadoras.

Analisando o desenvolvimento do porto de Santos a partir de dados obtidos junto ao Ogmo local, e usando uma série anual logo após a implantação da Lei $\mathrm{n}$ 8.630, constata-se que a movimentação de contêineres e carga geral é permanentemente crescente, como mostram as figuras 1 e 2 .

\section{Figura 1}

Movimentação anual de contêineres no porto de Santos

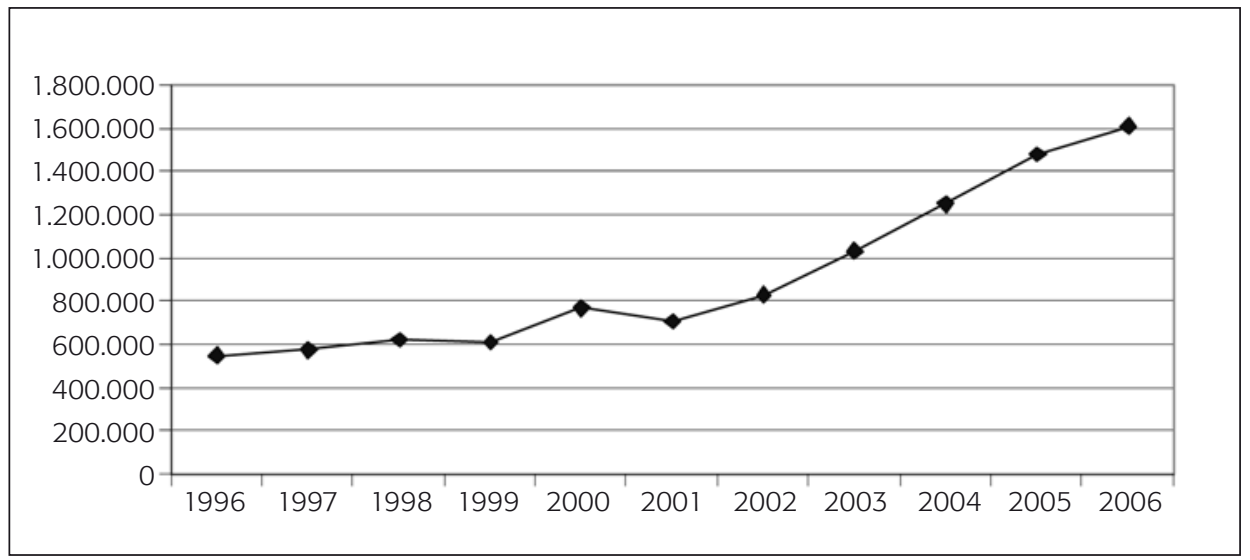

Fonte: Codesp - Santos.

Figura 2

Movimentação anual de carga geral no porto de Santos

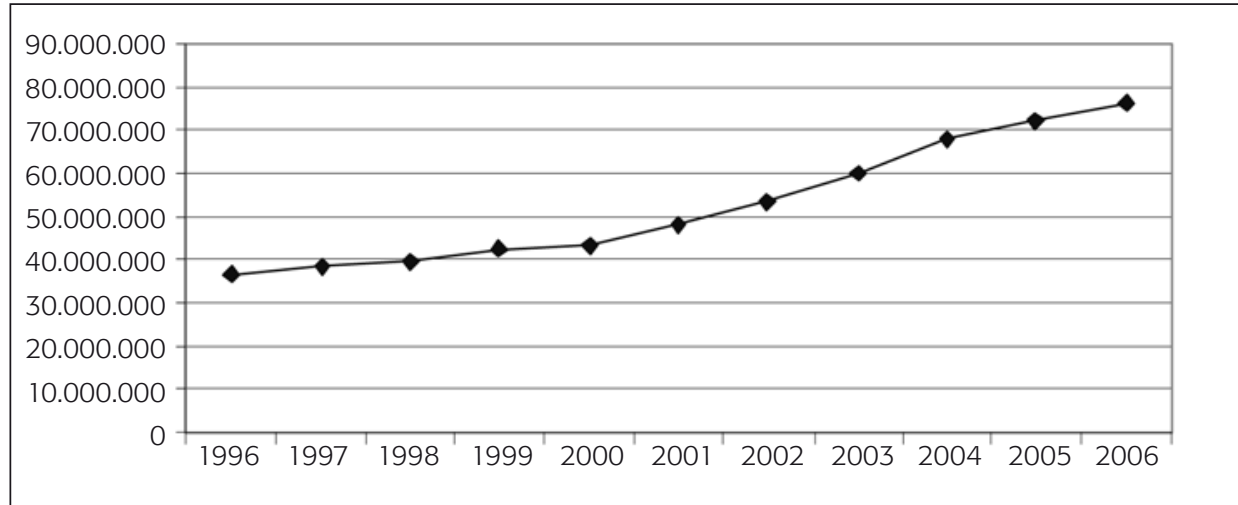

Fonte: Codesp - Santos 
Analisando a demanda por mão-de-obra mais recente requerida por esse crescimento, verificamos uma redução média no ano de 2006, conforme figura 3:

Figura 3

Recrutamento de mão-de-obra no porto de Santos: anos selecionados

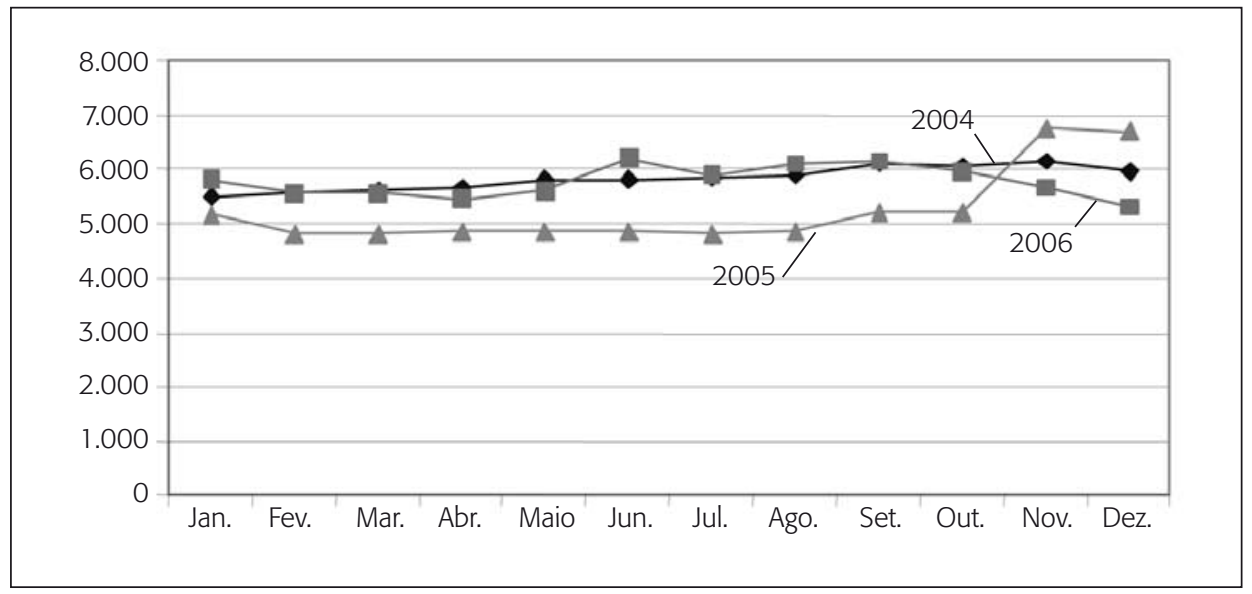

Fonte: Ogmo - Santos.

A redução da força de trabalho tem sua natureza no art. 57 da Lei no 8.630:

Art. 57. No prazo de cinco anos contados a partir da publicação desta Lei, a prestação de serviços por trabalhadores portuários deve buscar, progressivamente, a multifuncionalidade do trabalho, visando adequá-lo aos modernos processos de manipulação de cargas e aumentar a sua produtividade.

$\S 1^{\circ}$ Os contratos, as convenções e os acordos coletivos de trabalho deverão estabelecer os processos de implantação progressiva da multifuncionalidade do trabalho portuário de que trata o caput deste artigo.

§2 Para os efeitos do disposto neste artigo a multifuncionalidade deve abranger as atividades de capatazia, estiva, conferência de carga, conserto de carga, vigilância de embarcações e bloco.

$\S 3^{\circ}$ Considera-se:

I - Capatazia: a atividade de movimentação de mercadorias nas instalações de uso público, compreendendo o recebimento, conferência, transporte interno, abertura de volumes para a conferência aduaneira, manipulação, arrumação e 
entrega, bem como o carregamento e descarga de embarcações, quando efetuados por aparelhamento portuário;

II — Estiva: a atividade de movimentação de mercadorias nos conveses ou nos porões das embarcações principais ou auxiliares, incluindo o transbordo, arrumação, peação e despeação, bem como o carregamento e a descarga das mesmas, quando realizados com equipamentos de bordo.

Segundo a direção do Sindicato dos Estivadores (2007), a redução média da mão-de-obra no ano de 2006 deveu-se a acórdão judicial obtido pelos operadores portuários com base no art. 57.

Os estivadores, para assegurar algumas garantias, fizeram um acordo que elevasse o ganho dos trabalhadores, além de benefícios como vale-refeição e vale-transporte. Além disso, foi criado um plano de desligamento voluntário (PDV), em que 223 trabalhadores se desligaram e receberam cada um $\mathrm{R} \$ 30$ mil.

O resultado culminou na redução de $10,8 \%$ da força de trabalho no ano de 2006 comparativamente ao ano 2005. A massa salarial declinou 9,6\%.

O atual estágio de transformação no porto de Santos ainda não consolidou a fase de redução de custos, característica dos serviços portuários que utilizam capital intensivo para atender amplas economias de escala que viabilizem padrões desejáveis de competitividade. A infra-estrutura (cais, pátios, áreas de armazenamento) e a superestrutura (guindastes, tratores, caminhões, empilhadeiras, imóveis) portuárias ainda apresentam tamanhos operacionais reduzidos, com problemas de congestionamentos que desembocam em custos incompatíveis, impedindo que o capital privado alcance taxa de retorno razoável no médio prazo.

A expansão está em movimento, pois a Companhia Docas do Estado de São Paulo - Codesp (autoridade portuária no porto de Santos) projeta uma capacidade máxima de tonelagem possível de ser movimentada no porto de 110 milhões de toneladas, acima das 76 milhões de toneladas movimentadas em 2006.

A combinação produtividade do trabalho crescente e rendimento médio do trabalho decrescente são os pilares que ainda vão permanecer até o ponto em que os custos da movimentação no porto se comparem aos custos dos portos mundiais competitivos. Para se tornar competitivo em escala global, o porto de Santos adotou a estratégia de, no atual estágio de transformação, flexibilizar (para baixo) a massa salarial, reduzindo a quantidade de trabalhadores nos postos de trabalho e mantendo crescente o volume de contêineres e de carga geral movimentados ao longo dos anos. Segundo o Sindicato dos 
Estivadores de Santos, o crescimento projetado a partir da solução dos impasses que impedem o aumento da produtividade (aumento do calado para 17 metros, construção de perimetrais, sistema viário, ajustes no número de homens por terno de trabalho e introdução de novos operadores portuários) produzirá uma redução no número de trabalhadores correspondente a 40\% dos atuais 5 mil em trabalho.

A presença de um novo conceito de produção com base em operações mais enxutas, em que a especialização flexível é a tônica, eliminando do processo os trabalhadores de baixa qualificação, é um momento de perplexidade, de acordo com o relato a seguir.

o nosso padrão de vida caiu muito e é preciso entender que o estivador é uma categoria que lida com 10 tipos de equipamentos diferentes e é remunerado como um qualquer, ele trabalha com ponte rolante, máquina de esteira, pá carregadeira, o estivador faz tudo isso por uma remuneração só, mudar a cultura do passado para a atual é complicado porque hoje tem um grande contingente de estivador novo, só que esse estivador novo é o filho do estivador antigo, é o sobrinho, é o primo, então foi passada para eles a cultura dos antigos, então hoje para nós chegarmos num salão de assembléia e passar para o trabalhador que ele tem que ficar a bordo, que ele tem que preservar o mercado de trabalho dele, que ele tem que fazer o trabalho com carinho e tal, é difícil a gente transmitir isso pra eles, a cultura deles está ainda na cultura antiga, essa questão de cultura a gente tem que trabalhar muito em cima.

A cultura do estivador mostra a sua força no processo de transmissão de valores de pai para filho. O sistema de transmissão dos valores entre os parentes é o sistema unificador na vida dos estivadores. Eles construíram relações de pai com filho não só pela posição na produção, mas também porque se relacionavam como pai e filho.

A noção de multifuncionalidade está na ação objetiva do trabalho há muito tempo, contudo o seu significado remete a um contexto onde os equipamentos não eram poupadores de mão-de-obra, o que explica a queda do padrão de vida.

A adesão dos estivadores antigos e novos às novas formas de organização não ocorre porque os elementos culturais que davam significado à existência da profissão e eram expressão da própria vivência estivadora (autonomia, controle da organização, pertencimento, hierarquia consentida) não têm esse significado na nova ordem cultural, contudo há percepção sobre os novos sig- 
nificados ordenados pela cultura em mudança, o que leva o sindicato a inscrevê-los na agenda de trabalho.

\section{Considerações finais}

A modernização dos portos é um caso particular da inserção brasileira no processo global de comércio internacional em um setor que teve a intervenção do Estado como fator de dinamização da economia nacional. Essa inserção se inscreve na articulação estrutural do capital dos últimos 35 anos que, na busca de reorganização dos espaços da produção de valor sob formas novas tecnologicamente mais desenvolvidas, proporcionou uma transformação global que trouxe dimensões qualitativas novas para a vida dos trabalhadores, em especial do setor portuário de Santos. As mudanças produzidas pelo processo de privatização da área portuária e as novas formas de controle social da produção advindas de formas mais desenvolvidas da tecnologia e da gestão do trabalho marcam as novas disputas entre o capital e o trabalho. Este artigo analisou a experiência de vida dos estivadores do porto de Santos, que nos remete à construção de significados que orientam os meios de produção historicamente constituídos e a percepção que eles adquirem de si próprios e dos objetivos das suas vidas. Não se trata de alguma força exterior atuando sobre um material bruto, nem tampouco existe a suposição de que essa experiência foi gerada espontaneamente pelo sistema produtivo. Vimos que as consciências se estruturaram nas formas simbólicas de dominação e de resistência, o que representa a genética do processo histórico.

Hoje, a mudança implica a difusão de um novo processo produtivo, mais sistêmico, que leva à outra maneira de pensar a divisão do trabalho e a uma concepção renovada do lugar do indivíduo na produção, e que, neste atual estágio de transição, encontra um sujeito impregnado das ordens culturais passadas que lhe deram sentido de estabilidade. Na realidade o significado de "ser estivador" inscrito na ordem cultural em que se desenvolveu a profissão até 1993 não mais existe, e o novo significado, que define toda a ação futura ainda não emergiu, porque a cultura que impõe a ordem significativa sobre o processo instrumental (a transformação) não contém ainda a estrutura de realidade manifesta na produção. Os movimentos objetivos da transformação não produziram conseqüências determinadas porque não se agregaram paulatinamente às coordenadas da ordem cultural. Como vimos, a Lei no 8.630 trata da questão estrutural portuária e não há cláusulas sociais nos artigos que afetam diretamente a vida dos trabalhadores. A questão fundamental é que os 
aspectos materiais estão separados dos sociais como se a satisfação das necessidades pela produção não tivesse vínculos com a relação entre os homens. Os componentes culturais se desenvolvem em termos de propriedades materiais e sociais e na experiência portuária eles foram pensados como deduzidos da ordem econômica.

Os estivadores são homens que experimentam suas ações e relações produtivas em transformação como interesses, necessidades e antagonismos, trata-os em seguida em sua consciência e sua cultura das mais complexas maneiras e em seguida agem, por sua vez, sobre a situação determinada, ou seja, precarização.

A cultura não é expressão das formas de produção, pelo contrário, as formas de produção é que se desdobram em termos da cultura, ou seja, não é mais a sua própria forma, mas sim significado. Se a produção em transformação, expressa na lei, não incorpora as relações sociais fundamentais, seu significado, contrastado com o passado, é naturalmente rejeitado e os impasses permanecem.

\section{Referências bibliográficas}

ABRAMO, L. O resgate de dignidade. Greve metalúrgica e subjetividade operária. São Paulo: Unicamp e Imprensa Oficial, 1999.

CARVALHO, R. Q. Tecnologia e trabalho industrial. Porto Alegre: L\&PM Editores, 1987.

FLEURY, A. Rotinização do trabalho: o caso das indústrias mecânicas. In: FLEURY, A.; CORREA, Afonso Carlos; VARGAS, Nilton (Orgs.). Organização do trabalho. São Paulo: Atlas, 1983.

GEERTZ, Clifford. A interpretação das culturas. Rio de Janeiro: LTC, 1989.

GITAHY, C. Maria Lucia. Ventos ao mar: trabalhadores no porto, movimento operário e cultura urbana em Santos, 1889-1914. São Paulo: Unesp, 1992.

. Processo de trabalho e greves portuárias - 1889-1910: estudo sobre a formação da classe operária no porto de Santos. São Paulo: Vértice, 1987.

. Porto de Santos. In: PRADO, Antonio Arnoni (Org.). Libertários no Brasil. São Paulo: Brasiliense, 1986. 
GITAHY, L.; LEITE, M.; RABELO, F. Reestruturação produtiva e a empresa: programas de qualidade, políticas de gestão de recursos humanos e relações industriais. Projeto Estudo da Competitividade da Indústria Brasileira. Estudo Temático 3. Bloco Temático V: Condicionantes sociais da competitividade, Campinas, 1993.

GODOY, A. M. Golberg. Transformações tecnológicas e mudanças nas relações entre o porto e a cidade de Paranaguá. Revista Paranaense de Desenvolvimento, Curitiba, n. 99, p. 5-25, jul./dez. 2000.

HOBSBAWM, Eric. Mundos do trabalho — novos estudos sobre a história operária. São Paulo: Paz e Terra, 2000.

LARAIA, Roque de Barros. Cultura: um conceito antropológico. Rio de Janeiro: Zahar, 2000.

LEITE, Márcia de Paula. O futuro do trabalho: novas tecnologias e subjetividade operária. São Paulo: Scritta, 1994.

2003.

. Trabalho e sociedade em transformação. São Paulo: Perseu Abramo,

LUCCI, Cíntia R.; SCARE R. Fava.Custos de transação no ambiente portuário: uma aplicação da nova economia institucional para o porto de Santos. In: SEMEAD, 7. Anais... Seminários em Administração. São Paulo: FEA/USP, 2004.

MANFREDI, S. M. Trabalho, qualificação e competência profissional - das dimensões conceituais e políticas. Educação \& Sociedade, Campinas, São Paulo, v. 64, p. 13-49, 1998.

PAOLI, Maria Célia. Os trabalhadores urbanos nas fala dos outros. In: Cultura e identidade operária: aspecto da cultura da classe trabalhadora. Rio de Janeiro: Marco Zero, 1987.

PIERDOMÊNICO, F. Imprensa - Assessoria de Comunicação Social. São Paulo: Codesp, 2005.

POCHMANN, Márcio. Produtividade e emprego no Brasil dos anos 90. Campinas: Unicamp, 1997.

REVELLI, M. Le due destre, Bollati Boringhieri. In: Oito hipóteses sobre o pós-fordismo. Torino, 1996.

RUAS, R. Efeitos da modernização sobre o processo de trabalho — condições objetivas de controle na indústria calçadista. Porto Alegre: FEE, 1985.

SAHLINS, M. Cultura e razão prática. Rio de Janeiro: Zahar, 2003. . Cultura na prática. Rio de Janeiro: UFRJ, 2004. 
. História e cultura: apologias a Tucidides. Rio de Janeiro: Zahar, 2006.

SALERNO, M. S. Trabalho e organização na empresa industrial integrada e flexível. In: Novas tecnologias, trabalho e educação. São Paulo: Vozes, 1994.

SARTI, Ingrid. O porto vermelho: os estivadores santistas no sindicato e na política. Rio de Janeiro: Paz e Terra, 1981.

SILVA, F. Teixeira da. Operários sem patrão — os trabalhadores da cidade de Santos no entreguerras. Campinas: Unicamp, 2003.

VELASCO, L. O. M. de; LIMA, E. T. As novas empresas mundiais de navegação determinam a evolução dos portos. Revista BNDES, n. 11, jun. 1999. 